\title{
Observations on the Anatomy of Teratological Seedlings.
}

\section{On the Anatomy of some Polycotylous Seedlings of Cheiranthus Cheiri.}

\author{
$\mathrm{BI}$ \\ H. S. HOLDEN, M.Sc., F.L.S., \\ Bacteriologist (Temporary), R.N. Hospital, Plymouth, \\ AND \\ DOROTHY BEXON, B.SC., \\ Late Research Scholar in Botany, University College, Nottingham.
}

With seventeen Figures in the Text.

THE discovery by one of us of a strain of wallflower which threw a favourable opportunity for an anatomical study of specific teratological polycotyly on a somewhat more extensive scale than had hitherto been possible.

The particular strain of Cheiranthus, in addition to producing all types of seedling from the tetracotylous to the normal dicotylous form, exhibited a number of other features of some interest. Among these may be mentioned an alteration in the time of flowering, the production of a rather delicate seedling as compared with more normal strains, and also a relatively high percentage of abortive seeds. Thus in a total sowing of 2 I 2 seeds, there were 123 failures, 56 normal seedlings, and 33 abnormal ones.

The number of abnormal seedlings obtained from this source was augmented by the collection of some specimens from a common garden variety, most of these apparently throwing a few polycotyls.

The total number of polycotylous seedlings examined was fifty-four, and these fell into the following groups, as far as one could judge from external characters :

$$
\begin{aligned}
& \text { Type of Seedling. } \\
& \text { Hemitricotyls } \\
& \text { Tricotyls } \\
& \text { Hemitetracotyls } \\
& \text { Tetracotyls }
\end{aligned}
$$$$
\text { No. of Seedlings. }
$$$$
\begin{array}{r}
9 \\
-\quad 32 \\
\hline
\end{array}
$$

[Annals of Botany, Vo1. XXXII. No. CXXVIII. October, 1918.] 


\section{Methods.}

The seedlings were uprooted at as early a stage as possible, and were preserved in methylated spirit. Considerable difficulty was experienced in finding a stain suitable for the very delicate seedlings. Although numerous combinations of stains were tried, Delafield's haematoxylin was the only reagent which gave satisfactory results. At a later stage in the investigation, however, when the more robust seedlings of the garden variety were microtomed, good results were obtained with carthamin in 70 per cent. alcohol, followed by Lichtgrün in clove oil.

\section{DESCRIPTION OF RESULTS.}

The structure of the normal seedling of Cheiranthus Cheiri has been fully described by Miss Thomas (20), so that no detailed account need be given here.

The slender seedlings show, in every case, a high level of transition.

The base of each cotyledon is occupied by a central 'double' bundle, which in the transition region 'rotates' ${ }^{1}$ to form one pole of the diarch root. With this brief summary we may proceed at once to the description of forms showing more or less pronounced polycotyly.

\section{HEMITRICOTYLS。}

The nine seedlings of this type which were examined showed all stages of hemitricotyly, ranging from forms with only a slight notch at the apex of the abnormal cotyledon, to others showing fission right to the base of the lamina (Fig. I). Usually the two halves of the bifurcated cotyledon were together of approximately the same size as the normal cotyledon (Fig. I, $a$ ), but in one or two instances each half was as large as a whole cotyledon (Fig. I, $b$ ).

One case of considerable interest showed a peculiar asymmetry in the methods of fusion of the two halves of the cotyledon (Fig. 2). One half retained the leaf tissues on both sides of the midrib, whilst the other gradually lost its tissues on the side nearer its fellow, so that at the point of junction of the two halves an irregular $Y$-shaped structure was formed. This, however, soon became symmetrical by the dying away of the extra flange.

The behaviour of the vascular bundles of the hemitricotylous seedlings is extremely interesting, and enables one to divide them into two distinct groups.

1 The terms 'transition' and 'rotation' are used in this paper as convenient conventionalities without implying adherence to the theories of seedling structure in which they originated. 
(a) In the seven seedlings comprising the first group the normal cotyledon has a typical double bundle, while the midrib of each half of the bifurcated cotyledon consists of a collateral bundle. Towards the base of the cotyledon, after fusion of the two halves has occurred, the collateral bundles approach one another, while the protoxylems rotate towards the middle line, and fuse so that ultimately the two function as a double bundle,
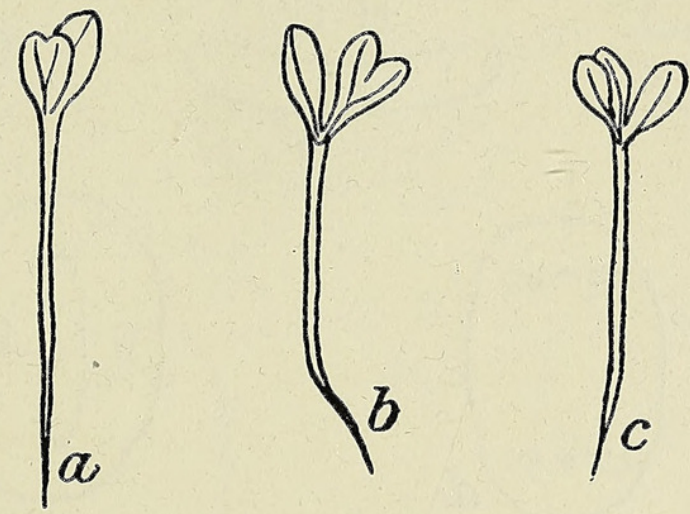

FIG. I. $a, b, c$. Hemitricotylous seedlings, showing three stages in the division of the abnormal cotyledon.
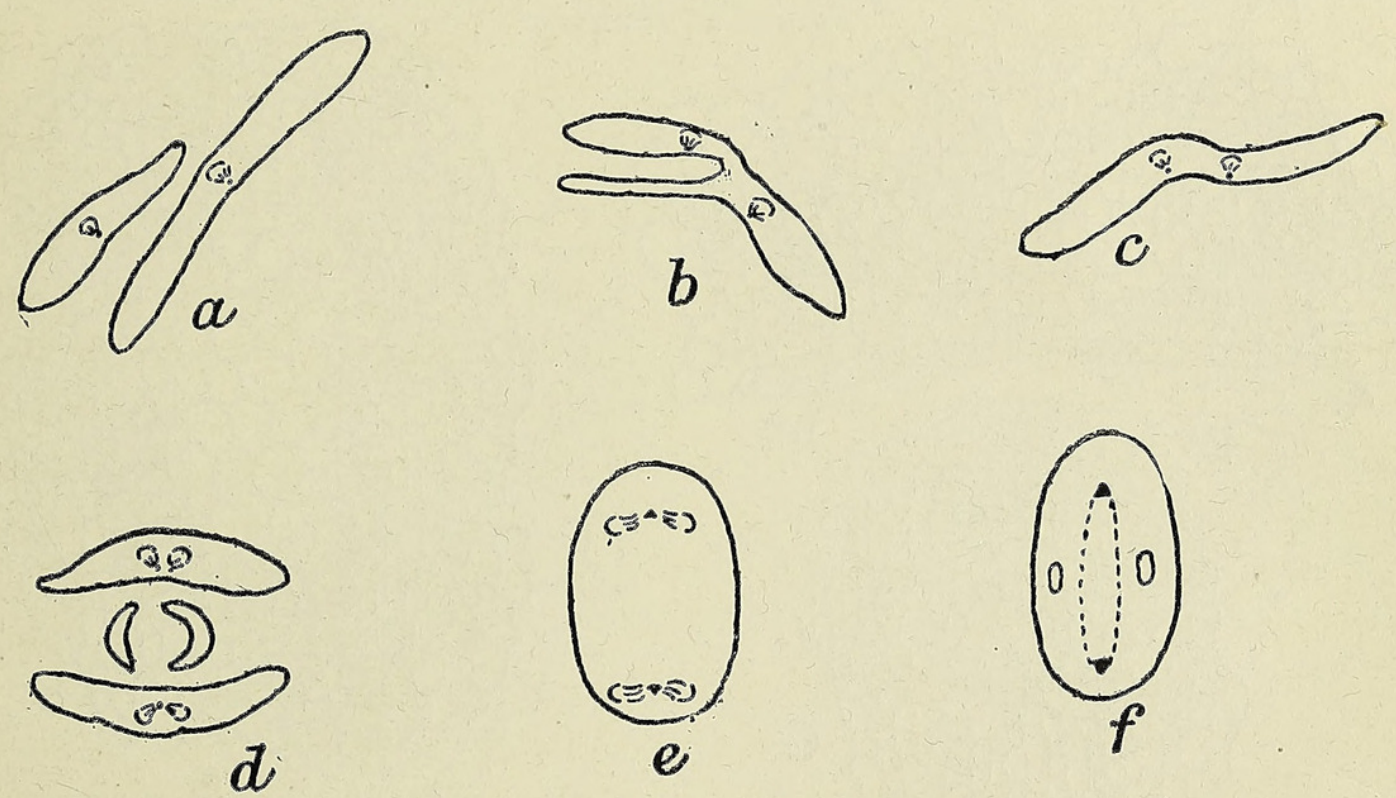

FIG. 2. $a-f$. Hemitricotyl, Type $a$. Diagrams $a, b, c$ show the asymmetrical union of two half cotyledons; the normal cotyledon is not shown. Diagrams $d, e, f$ show the structure lower down in this seedling.

producing, together with the double bundle of the normal cotyledon, a typical diarch structure (Fig. 3).

This condition is found in seedlings having the cotyledon split nearly to the base, as well as in those which are merely notched, the only variation being in the level at which the two collateral bundles unite. This union may occur in the lower portion of the cotyledon lamina, in the petiole, or even at the apex of the hypocotyl, but the point of fusion bears no close 
relation to the extent of fission, for it may occur at approximately the same level in a cotyledon showing an apical notch, as in one which has a deeply split lamina, the union taking place in both instances in the cotyledon petiole. Even when the two half bundles are a little more widely separated
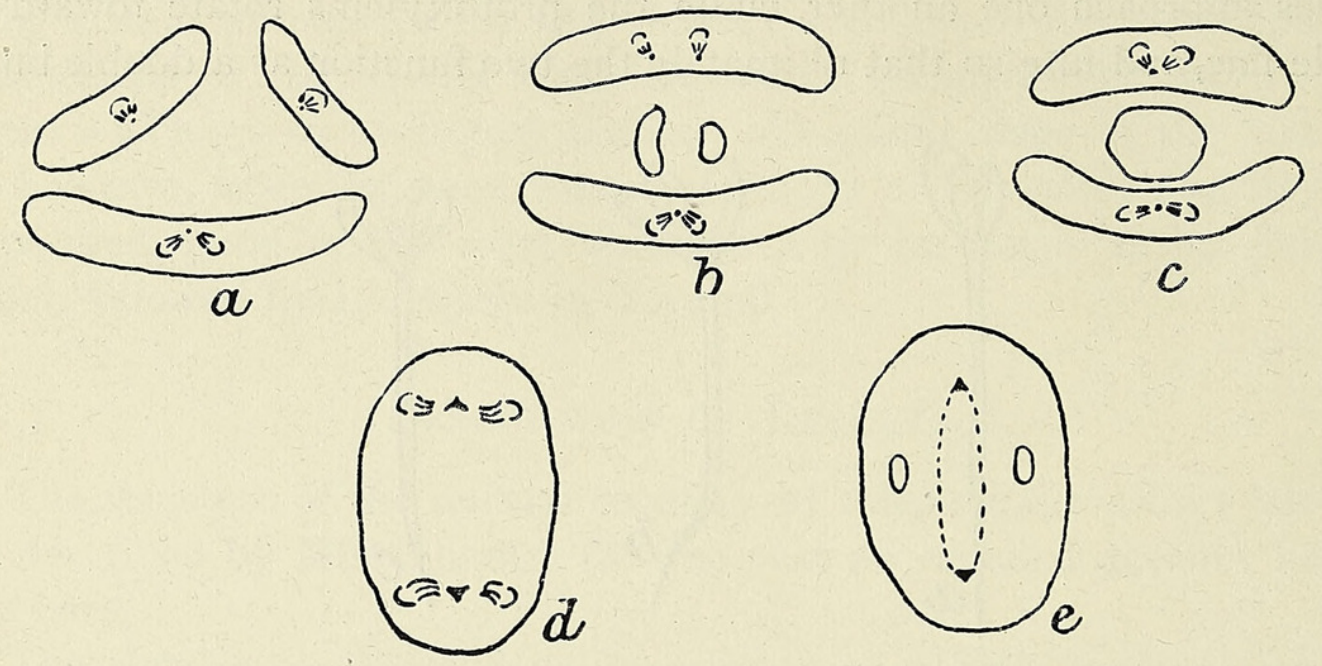

FIG. 3. $a$-e. Hemitricotyl, Type $\alpha$. Diagrams showing the characteristic features of this type.
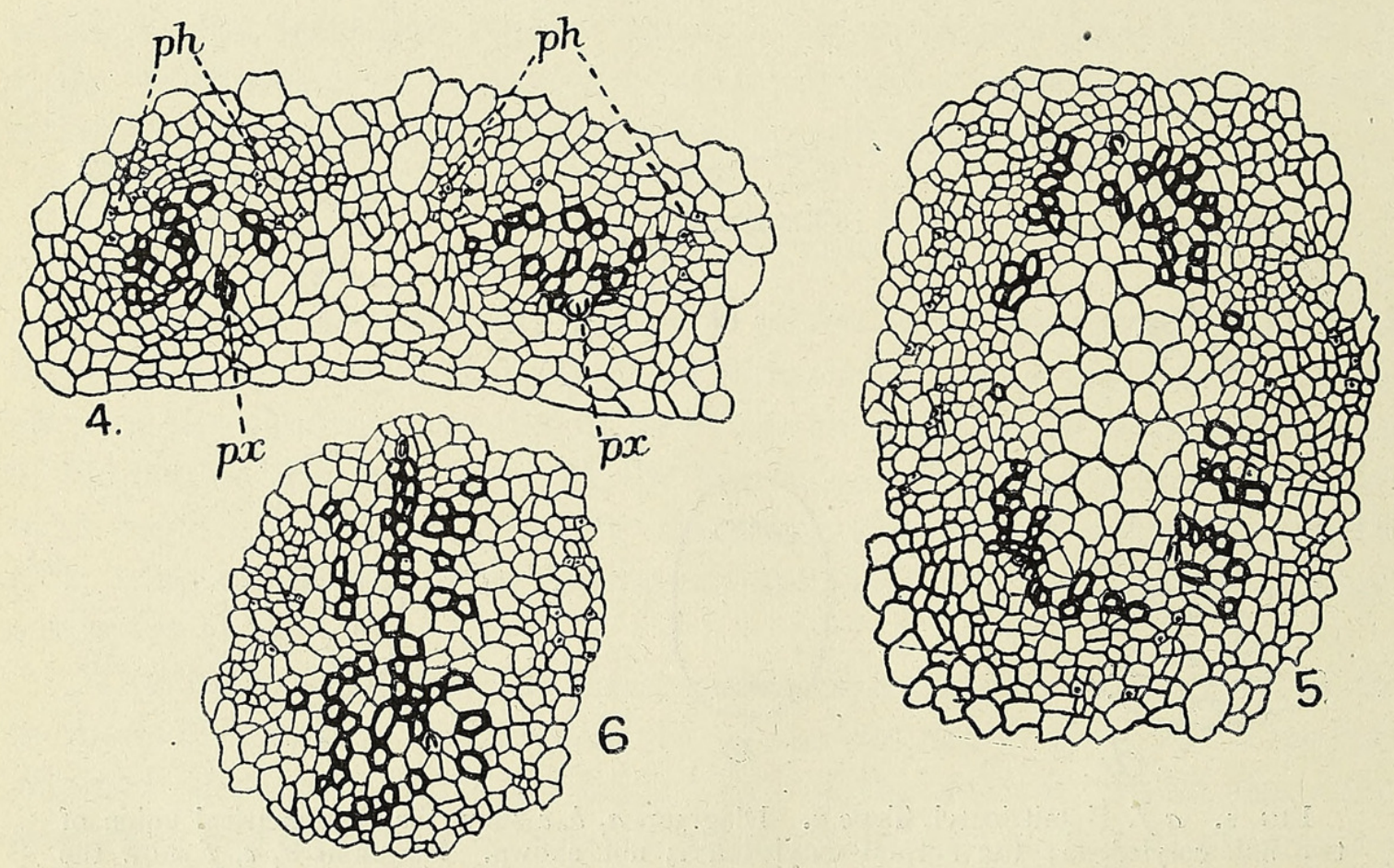

FIG. 4. Hemitricotyl, Type $\beta$. Transverse section. Petiole.

Fig. 5. Hemitricotyl, Type $\beta$. Transverse section near apex of hypocotyl.

Fig. 6. Hemitricotyl, Type $\beta$. Transverse section near base of hypocotyl.

$p h=$ phlcem $; p x=$ protoxylem. All three figures show a considerable development of secondary xylem.

at the node than in the normal double bundle, the rotation still occurs at the usual level.

(b) The second group of hemitricotyls comprises two seedlings only, and in these the vascular strands of the abnormal cotyledon show considerable differences in structure and behaviour compared with those of the first 
group. Each half of the bifurcated cotyledon exhibits a couble-bundle midrib (Fig. 4), which gradually approaches its fellow until the adjacent phloems fuse (Fig. 7). This phase is followed by the reduction in size of the adjacent xylems and their fusion, so that a W-shaped structure, in
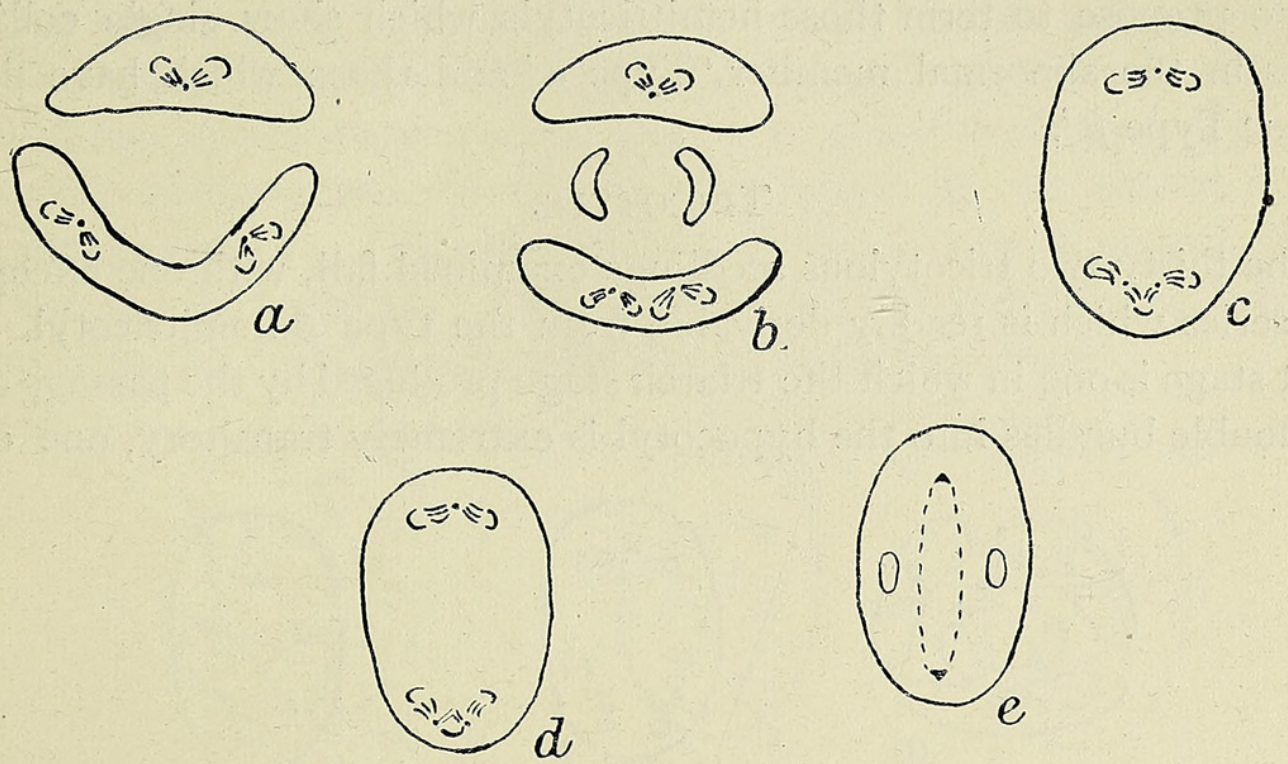

FIG. 7. $a-e$. Hemitricotyl, Type $\beta$. Diagrams showing the initiation of triarchy and its reduction to diarchy by fusion.

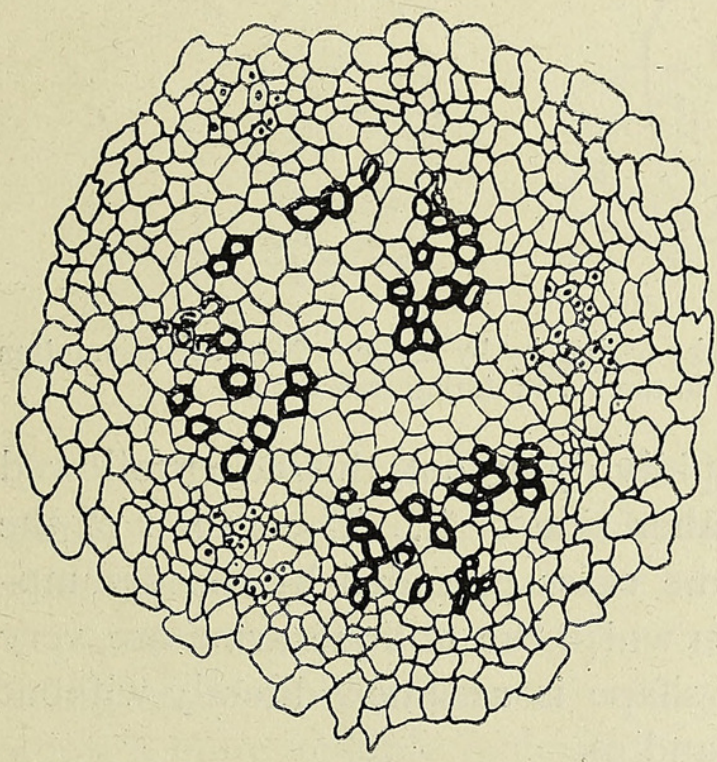

FIG. 8. Tricotyl. Transverse section near apex of hypocotyl.

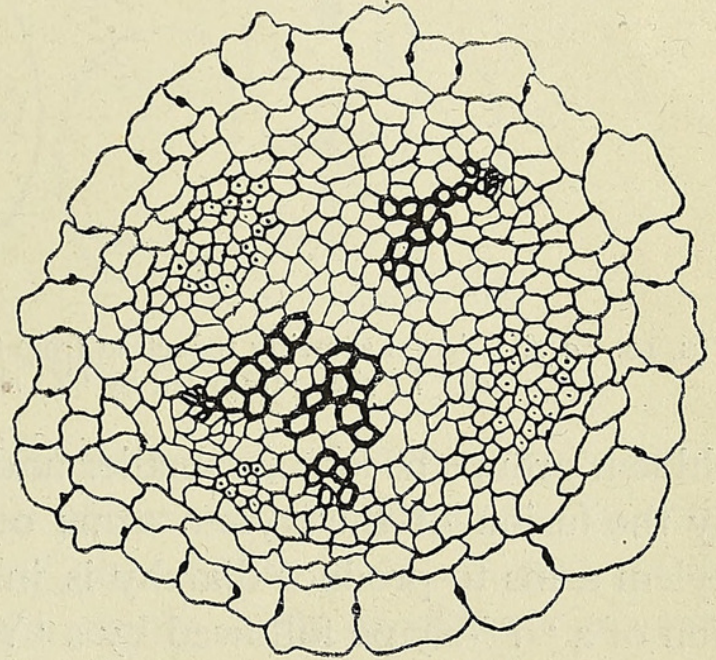

Fic. 9. Tricotyl. Transverse section at base of hypocotyl. Note the indications of approaching fusion between two of the poles and the reduction in the size of the phloem group between them.

which the median portion is much flattened, results. This encloses a small phloem group, and is flanked laterally by two other phloem groups (Fig. 5). Ultimately, in one case at the base of the cotyledons and in the other in the hypocotyl, the fusion of these double bundles becomes more intimate, and the enclosed phloem strand dies out (Fig. 6). The two xylems also fuse as they pass down the hypocotyl, so that a diarch plate finally results. In both 
the seedlings of this second group the cotyledon is split almost to the base. In the seedlings of the first group the epicotyledonary leaves, when present, are invariably two in number; but in one seedling of the second type there are three epicotyledonary leaves.

We propose to term those hemitricotyls which show single collateral bundles in the abnormal member 'Type $a$ ' and those which have double bundles 'Type $\beta$ '.

\section{TRICOTYLS.}

The thirty-two tricotylous seedlings examined fall, with one exception, into a series which is readily derivable from the type $\beta$ hemitricotyl. The earliest stage is one in which the triarch stage produced by the passage of the three double bundles into the hypocotyl is extremely transitory, one of the
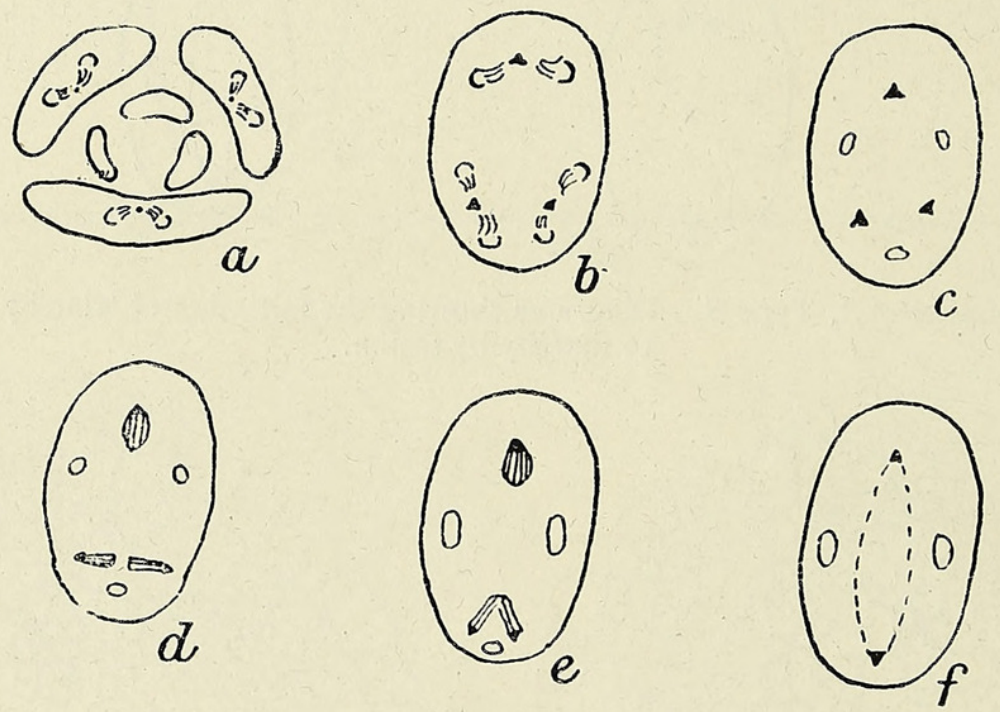

FIG. Io. $a-f$. Tricotyl showing reduction from triarchy to diarchy by fusion. Note the assumption of ' $T$ ' shape followed by ' $Y$ ' shape in the xylem during transition.

phloem groups becoming smaller and rapidly dying out, this being followed by the fusion of the xylem arms on either side of it. The fusion of the xylem arms to produce diarchy is in some cases preceded by the assumption of $a$ ' $T$ '-shape followed by a ' $Y$ ', in which the oblique arms are very short (Fig. IO); in other cases the ' $Y$ '-shape is assumed directly without the intervention of a ' $T$ ' stage (Figs. 8 and 9 ).

From the type in which diarchy is rapidly developed, a series of stages is found in which diarchy is produced at a later and later stage, until it appears only in the apical region of the root, the hypocotyl and the major portion of the root showing a triarch structure. In other cases the apex of the root shows a ' $Y$ ' structure with two phloem groups, whilst others again show a distinctly unequal development of the xylem plate, two of the arms being less robust than the remaining one, and showing a relatively small phloem group between them. There is little doubt that if these seedlings had been allowed to develop further, the apical portion of the root would 
have ultimately shown a diarch structure. Finally, there are those forms in which triarchy is established and persistent throughout; these, which include more than half the total number of tricotyls examined, forming the culmination of the series (Fig. I I).

One further point of interest must be noted. In one instance reduction from the triarch to the diarch condition was brought about not by the fusion of two xylem plates and the disappearance of the intervening phloem, but by the disappearance of a xylem plate, and the subsequent fusion of two phloem groups. The protoxylem was the first to disappear, followed later by the metaxylem. The possible significance of this interesting difference in the mode of reduction will be dealt with later.
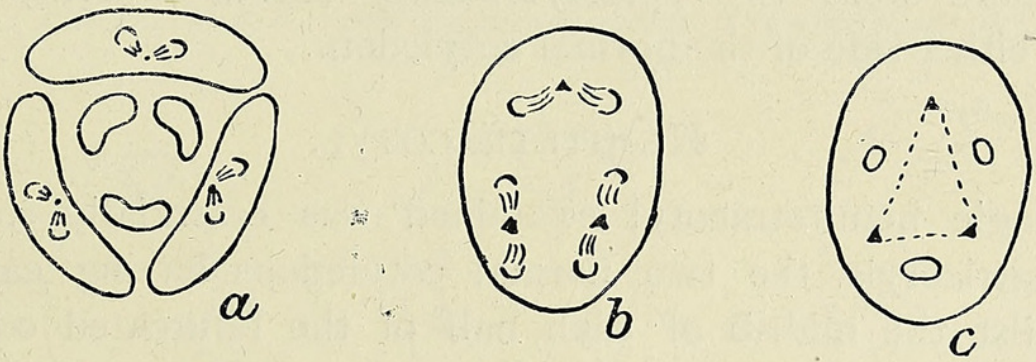

FIG. II. $a-c$. Tricotyl showing persistent triarchy.
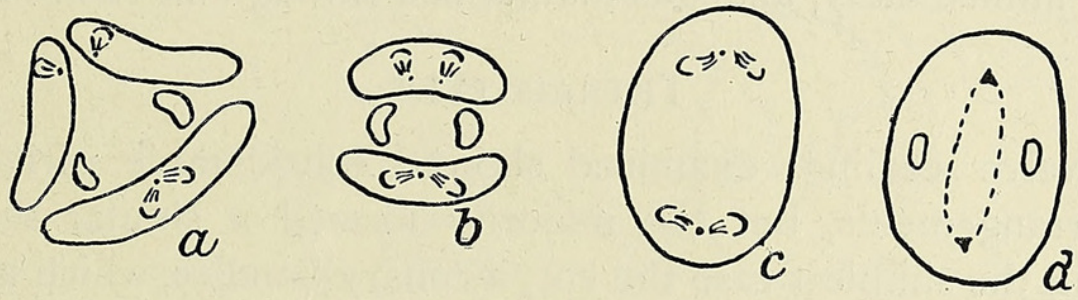

FIG. I2. $a-d$. Tricotyl, Type $a$.

In the tricotylous as in the hemitricotylous seedlings morphological characters gave no clue to the behaviour of the vascular strands. In some cases thet hree cotyledons were of equal size, whilst in others two cotyledons were considerably smaller than the third; both conditions, however, being found to be associated with persistent triarchy. A feature which gave a much more reliable indication was found in the slightly earlier fusion of two of the cotyledons, as where this precocious union occurred it was usually followed by the ultimate union of the associated xylem poles.

The double bundles themselves showed a considerable variation in the degree of separation of the metaxylem elements of the triad, this being in some cases very pronounced, whilst in other cases the phloem only was double and the bundle appeared to have undergone lateral compression. No relationship could be traced, however, between the degree of compression and the ultimate fate of the vascular bundles.

Usually the young epicotyledonary leaves formed a trimerous whorl 
alternating with the cotyledons, but in one case only two epicotyledonary leaves were present. It is interesting to note also that in some instances the vascular bundles of the epicotyledonary leaves showed the 'doubleness' which is so characteristic of the cotyledonary strands.

The exceptional case referred to at the beginning of this section is derivable from a type $a$ hemitricotyl. In it two of the cotyledons possessed a collateral bundle, whilst the third showed a normal double bundle (Fig. 12). As they enter the hypocotyl the two collateral bundles are a little distance apart, but they commence to rotate and approach one another until the typical structure is produced, this occurring, however, at a rather lower level than in the case of the double bundle. Ultimately a diarch plate is formed. There were two epicotyledonary leaves present, these being situated on either side of the normal cotyledon.

\section{Hemitetracotyl.}

The single hemitetracotyl examined was essentially similar to the type a hemitricotyls, the two normal cotyledons having each a double bundle, whilst the midrib of each half of the bifurcated cotyledon was formed by a collateral strand. The two collateral strands behaved in transition as the constituent halves of a double bundle, so that triarchy was established immediately, and was maintained throughout the root.

\section{TEtracotyls.}

The twelve seedlings examined showed considerable variety in their vascular arrangements, but the majority formed a similar series to the tricotyls. In the simplest case the cotyledonary bundles, which are grouped in two obvious pairs, show a transient tetrarch arrangement at the top of the hypocotyl, this being followed by a reduction to diarchy without the intervention of a triarch stage, owing to the bundles fusing in pairs. This fusion is accompanied by the disappearance of the phloem group originally lying between each pair of xylem masses (Fig. I4).

The second type is one which leads up to stable tetrarchy and consists of the initiation of a tetrarch stage at the top of the hypocotyl, followed sooner or later by a reduction to the triarch condition (Fig. I 5). In some seedlings the tetrarch stage was very brief, but in others it was retained farther and farther down the hypocotyl, until finally the tetrarch arrangement obtained throughout (Fig. I6).

The reduction from tetrarchy to triarchy is accomplished in two different ways, the two methods being almost equally represented among the seedlings. In some instances reduction is brought about by the fusion of two of the xylem masses, this being preceded by the loss of the phloem lying between them (Fig. I5). In the second type of seedling the reduction is produced by the gradual dying out of one xylem plate and the fusion of 
the phloem groups on either side of it. In almost every example of this type the protoxylem disappears first, followed at a later stage by the
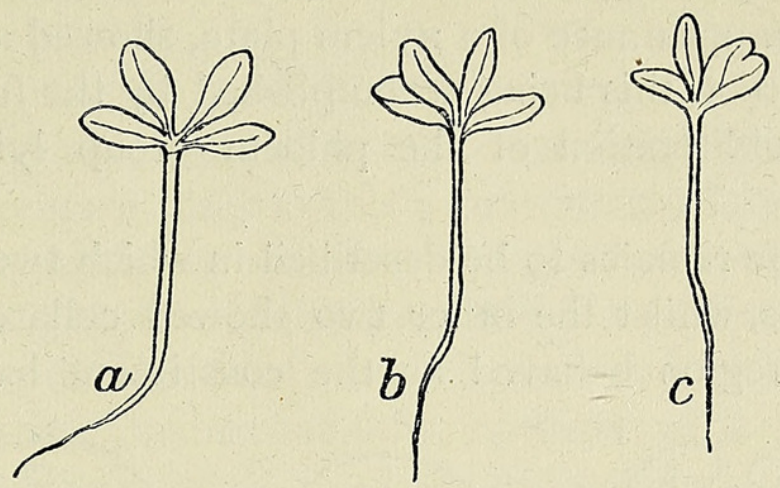

FIG. 13. $a, b, c$. Tetracotylous and hemitetracotylous seedlings.
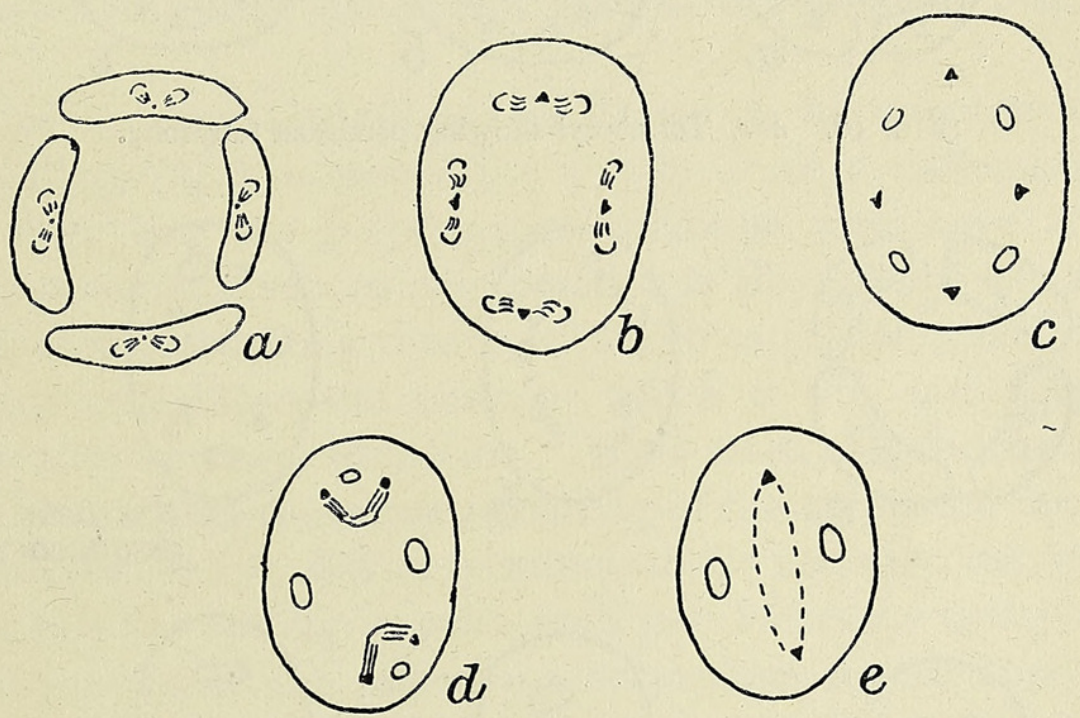

FIG. I4. a-e. Tetracotyl showing reduction from tetrarchy to diarchy by fusion.
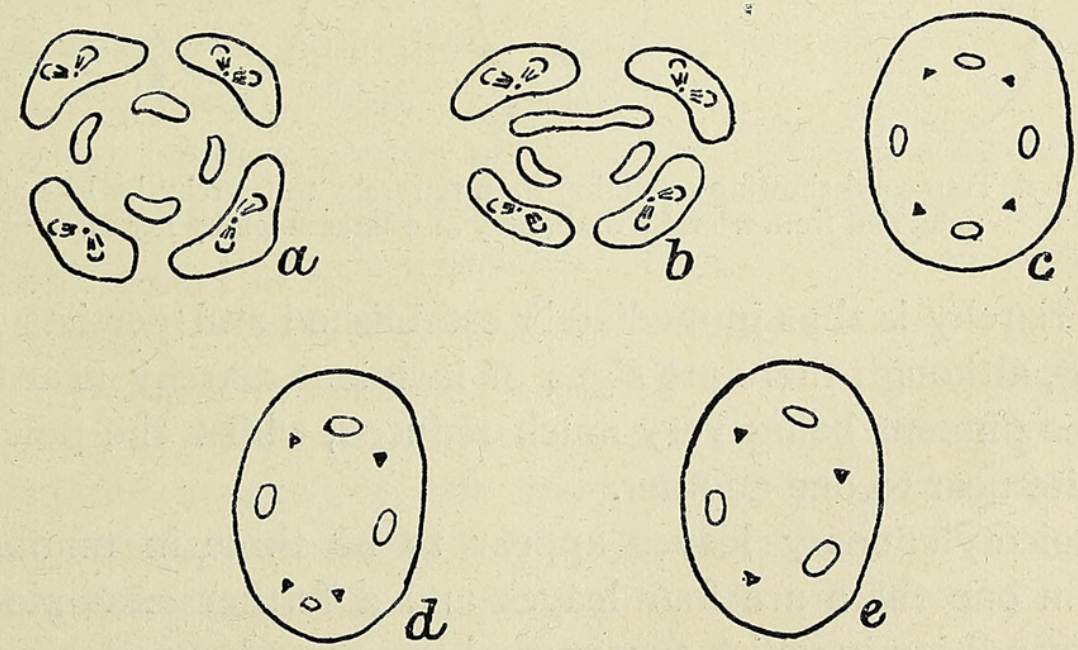

FIG. I5. a-e. Tetracotyl showing reduction from tetrarchy to triarchy by fusion.

metaxylem (cf. Compton [4], Cannabis sativa, Tricotyl D). In one case only does the metaxylem disappear, first leaving an isolated protoxylem 
which persists until a later stage, thus resembling the condition of affairs characterizing Phacelia tanacetifolia as reported by Compton (4).

In one case a seedling, which had shown reduction from tetrarchy to triarchy by the disappearance of a xylem plate, showed a further reduction to diarchy in the root, this being accomplished by the fusion of the xylem masses and the obliteration of the phloem group lying between them (Fig. I7).

One other type remains to be described in which two of the cotyledons had double bundles, whilst the other two showed collateral bundles which in the transition region behaved as the constituent halves of a double
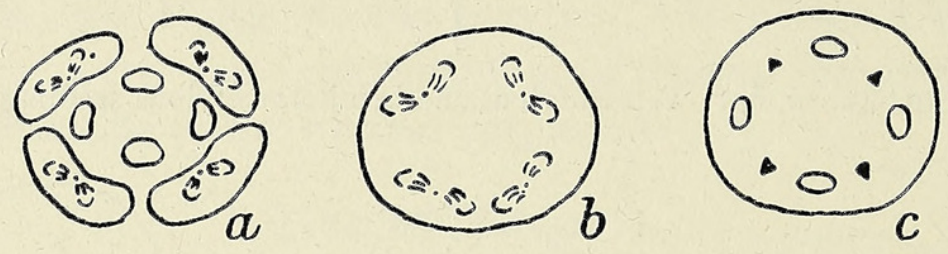

FIG. I6. $a-c$. Tetracotyl showing persistent tetrarchy.
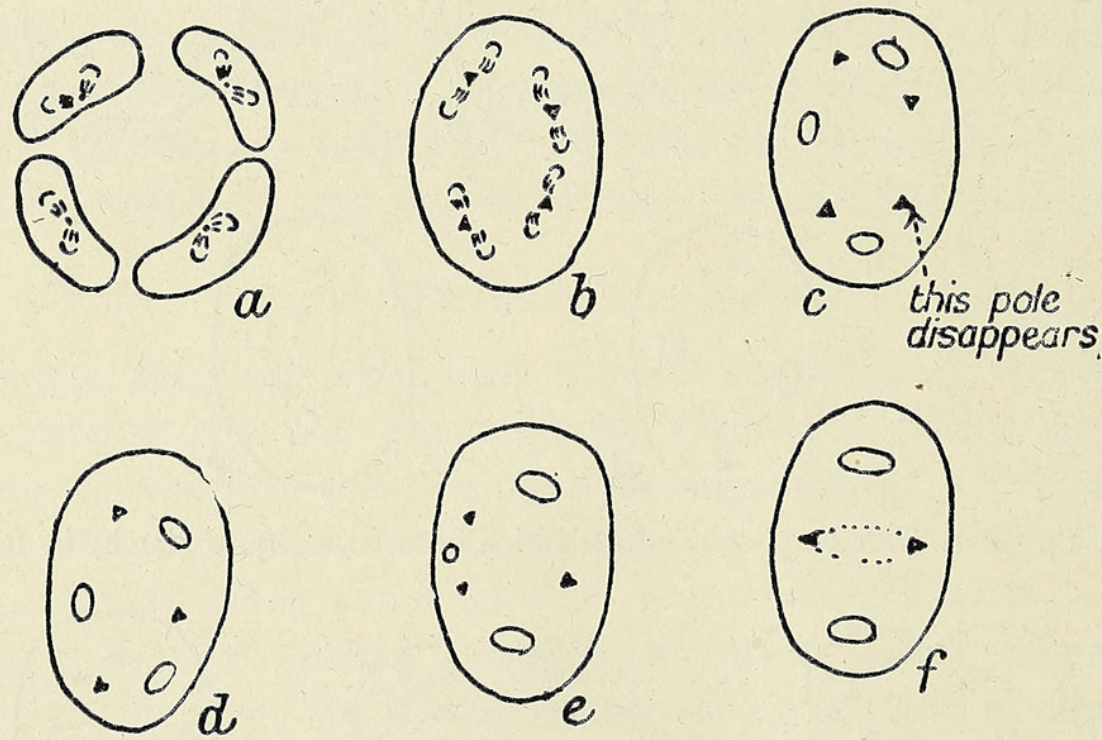

FIG. I 7. $a-f$. Tetracotyl showing reduction from tetrarchy to triarchy by loss of one xylem pole, and from triarchy to diarchy at a later stage by fusion.

bundle. Triarchy is thus immediately established and persists throughout the seedling, although there are signs of incipient diarchy near the apex of the root, one phloem being very much reduced, whilst the poles on either side are quite near to one another.

The epicotyledonary leaves appear to be three in number in most cases, but in one there are four leaves, and a further example shows the interesting condition in which two normal leaves and one exhibiting partial fission are evident (Fig. I $5, a, b$ ).

It will thus be perceived that in the assumption of tetrarch symmetry there is a distinct tendency on the part of the first epicotyledonary leaves to 
lag behind the members of the cotyledonary whorl, a feature which was evident to some extent in the tricotylous and hemitricotylous series, and which has already been noted by Compton (4) in Cannabis sativa.

\section{Discussion.}

Although the references to polycotylous seedlings are relatively numerous in botanical literature, they are as a rule merely incidental, and in the majority of cases the anatomy of such seedlings does not seem to have been investigated. This is especially the case with the earlier papers, which are little more than records with brief anatomical notes in one or two instances.

Léger (14) has dealt somewhat fully, however, with the abnormal seedlings which are frequently found in Acer platanoides, and Dangeard (6) in his investigations on the anatomy of coniferous seedlings has also attempted a classification of the seed leaves met with in the polycotylous genera of that group.

The series of papers by Hill and de Fraine on the anatomy of gymnospermous seedlings (9) is, however, the first in which a systematic attempt is made to show how the polycotylous condition may have arisen; and although this occupies a subordinate position in the general scheme of their investigation, they elaborate a theory of whole cotyledons, half cotyledons, and subsidiary cotyledons, the basis of which is the part taken by the cotyledonary strand in root formation. Thus whole cotyledons are distinguished by the fact that the vascular bundle of the cotyledon forms a rootpole quite independently; half cotyledons, on the contrary, being characterized by their bundles uniting in pairs, each pair forming a root-pole; whilst the vascular bundles of the subsidiary cotyledons merely fuse on to the other bundles without taking any direct part in root formation. This theory they support by a considerable body of evidence, and they interpret certain cases as illustrating the 'promotion' of subsidiary and half cotyledons to higher rank as whole cotyledons.

Compton (4), in that section of his paper dealing with schizocotyly, criticizes certain details of this scheme, taking exception to the class of subsidiary cotyledons, and to the idea of 'promotion', and to these criticisms Hill and de Fraine (13) have replied in a further paper.

In addition to the papers of Hill and de Fraine, and Compton, a number of isolated references to the anatomy of polycotylous seedlings are to be found in the majority of the more recent contributions to seedling anatomy, and these will be referred to when necessary.

With regard to the seedling anatomy of the wallflower itself, as mentioned above, that of the normal plant has been described by Thomas (20) and also by Scott (17). In addition Thomas (20) mentions tricotylous specimens of Cheiranthus Cheiri and of Sisymbrium carpaticum, both showing persistent triarchy, and one of Matthiola tricuspidata in which a 
diarch root is produced by the early fusion of two of the double bundles, thus producing a further illustration of a transition stage from a type $\beta$ hemitricotyl. On the basis of our work we propose to put forward the following provisional explanation of the origin of the polycotylous condition. Polycotyly may arise in one of three ways, namely, either by cotyledonary fission, by the division of the growing point of the cotyledon, or by the displacement of one of the foliage leaves into the cotyledonary whorl. The first type of increase, by fission, we consider to be illustrated by our type $a$, in which each of the half cotyledons possesses a midrib of the collateral type. This we regard as derived from a double bundle by the wide separation of the constituent halves, with which has gone a loss of the median protoxylem. The protoxylem is indeed extremely transient in character even in the normal cotyledon, and it may well be that it is occasionally ontogenetically obsolete.

It will be noted that this method of cotyledonary increase owes its origin to the qualitative division of the parent cotyledon, and although the fission may, though rarely, occur so early that the tricotylous condition obtains, yet the bundles invariably behave as the constituent halves of a double bundle, giving rise to one pole of the root.

This type of cotylar increase is extremely common, and a consideration of Hill and de Fraine's work will show that the majority of their half cotyledons ${ }^{1}$ belong to the same category. It is notable that in two of the seedlings described by them, namely, Pinus contorta var. Murrayana, series A (cotyledons $\mathrm{C}$ and $\mathrm{D}$ ), and $P$. sylvestris, series A (cotyledons $d$ and $e$ ), their origin is shown by the fact that the median resin duct passes to one member of the pair and assumes in the hypocotyl the characteristic position found in the whole cotyledon. In our opinion, however, cotylar fission of the qualitative type constitutes a finite series, and has led to no further developments.

Cotyledonary increase produced by the early division of the cotylar apex-our type $\beta$-is essentially different, being quantitative in character, and thus contrasting strongly with the division of type $a$. It is evident that this type of increase, which is illustrated by a perfectly graded series in our material, would offer an ideal method for the development of the polycotylous condition without calling in the aid of a system of 'promotions' which, to say the least, involves considerable morphological changes.

The initial member of such a series would be a type $\beta$ hemitricotyl in which the normal structure is established either in the basal portion of the

1 e. g. Cupressus torulosa, series C and D; C. mairocarpa, series B; Abies Balsamea, series A; A. pectinata, series $\mathrm{A}$ (and the six half cotyledons of series $\mathrm{B}, \mathrm{C}$, and $\mathrm{D}$ ); $A$. magnifica var. shastensis, Picea ajanensis, series A, B, C, and D; Cedrus atlantica, series A, B, and C ; C. deodara, Pinus Pinea, series A, B, and C; $P$. gerardiana, $P$. canariensis, $P$. contorta var. Murrayana, series A (half cotyledons $\mathrm{C}$ and $\mathrm{D}$ ); and $P$. sylvestris, series A (half cotyledons $d$ and $e$ ). 
bifurcated cotyledon or at the apex of the hypocotyl. This would be succeeded by tricotyly with the assumption of diarchy at the apex of the hypocotyl, the subsequent stages being provided by a progressively longer delay in the fusion of the vascular elements concerned until ultimately persistent triarchy is attained. Granted a similar shifting to an earlier stage of the apical quantitative division in phylogeny, the transition from dicotyly to polycotyly would be relatively simple. It will be obvious, moreover, that from such an initial stage a large range of possible developments is conceivable, since the process is capable of infinite repetition and may be augmented by a qualitative fission such as is illustrated by our type $a$ cotyledons.

A consideration of previous investigations will demonstrate that this type of cotyledonary bifurcation is of fairly frequent occurrence. Thus Lee (15) records an instance in Dimorphotheca pluvialis and in Bidenspilosa, and Guillaumin (8) in Schimus terebinthifolius. The seedlings of Acer platanoides described by Léger (14) all seem to fall within this category, though the elaboration of the lateral bundle systems produces further complications, whilst of Compton's material (4), hemitricotyls A and B, hemitricotyls C and $\mathrm{F}$, and all the tricotyls of Camnabis sativa, tricotyls D and $\mathrm{E}$ of Lepidium sativum, and the single hemitricotyl of Ulex europaeus conform exactly.

With regard to Hill and de Fraine's Gymnosperm material it will be perceived that the four half cotyledons in series $\mathrm{A}$, and the two half cotyledons in series B, Pinus australis, the four half cotyledons (C and D, G and $\mathrm{H})$ of Pinus insignis, series $\mathrm{B}$, the two half cotyledons of $P$. contorta var. Murrayana, series $\mathrm{I}$, the two half cotyledons of $P$. montana var. gallica, series $\mathrm{C}$, and the two half cotyledons $(f$ and $g$ ) of $P$. sylvestris, series $\mathrm{H}$, are also essentially similar. It is of extreme interest to note the behaviour of the median resin duct in the only two members of the above series figured by Hill and de Fraine, namely $P$. australis, series $A$, and $P$. syluestris, series $\mathrm{H}$, and contrast it with what obtains in those to which we have previously referred, as illustrating qualitative as distinct from quantitative cotylar division. Here it will be seen that each half cotyledon possesses a median resin duct flanked by the halves of a normal 'double bundle'. The resin ducts fuse at the apex of the hypocotyl, whilst the behaviour of the xylem and phloem resembles that described by us for similar cases in Cheiranthus.

One further instance from this important series of papers calls for comment, namely, that of Araucaria Cunninghamii, series A and B. It will be noted that Hill and de Fraine demonstrated that the appearance of tetracotyly is deceptive and that there are really only two deeply bifid cotyledons. The half cotyledons are each traversed by two collateral bundles which partially fuse near the apex of the hypocotyl. The four bundles thus produced pursue a completely independent course throughout the major 
portion of the hypocotyl, each ultimately fusing with its fellow to form the two poles of a diarch root. It will be perceived that these seedlings afford an admirable illustration of an advanced stage in the evolution of polycotyly along the lines we have indicated as probable.

In addition to these two methods by which the plant may become polycotyledonous, another possibility presents itself. Several investigators of seedling anatomy have reported the 'doubleness' of the vascular bundles of the early epicotyledonary leaves in some species.

Thus Davey (5) reports this in Fuglans spp., Fagus sylvatica, and Castanea sativa, while it is described by Thomas (20) in Cheiranthus maritimus and Draba Aizoon. It has also been observed by us in some of the Cheiranthus seedlings examined during this investigation. In Fuglans nigra the double bundles from the first two epicotyledonary leaves form, quite independently, two of the poles of the tetrarch root, and the same phenomenon is reported by Compton (3) in Caesalpinia sepiaria and in Pithecolobium Unguis-cati. Bearing in mind these facts and also that Hill and de Fraine (9) interpret some of the phenomena in the polycotylous gymnospermous seedlings as indicating that a plumular leaf has been displaced to the cotyledonary whorl, it seems quite possible that the cotyledon number may be increased by the precocious development and displacement of one of the epicotyledonary leaves, the double bundle of which shares directly in root formation. It is evident from these that the 'promotion' of a displaced epicotyledonary leaf to the rank of a whole cotyledon would not necessarily involve an intermediate phase as half cotyledon such as Hill and de Fraine suggest in their system of evolution. There is, however, no direct evidence of the displacement of an epicotyledonary leaf in our material. It has been pointed out previously that there are two methods of reduction of the root pole number, namely by fusion of poles, and by the loss of one xylem pole. This second method is described also by Compton (4) in Cannabis sativa, tricotyl D, and in the majority of the abnormal seedlings of Phacelia tanacetifolia. The bundle which shows this behaviour is regarded by Compton as belonging to a ' subsidiary' cotyledon, but with this interpretation we cannot agree, if the term 'subsidiary' is to be applied in the sense used by Hill and de Fraine. It is conceivable that the two methods of reduction are connected with different methods of cotylar increase, reduction by fusion occurring when polycotyly is produced by the division of the apex of the cotyledon, and reduction by disappearance appearing in seedlings possessing a displaced epicotyledonary leaf. The occurrence, however, of intermediate stages between fusion and suppression militates strongly against this interpretation of the method of reduction under consideration.

Thus in one or two Cheiranthus seedlings which showed reduction from triarchy to diarchy by fusion of xylem poles, one of the two poles became somewhat smaller than the other, just prior to fusion, thus presenting an 
appearance intermediate between ordinary fusion and reduction by the dying away of a xylem mass, and this intermediate condition has been noted in a more pronounced degree in some tricotylous seedlings of an undetermined species of Matthiola. Two of these show a loss of protoxylem in one of the two xylem plates which ultimately merge, whilst a third shows a loss of metaxylem, so that before fusion one xylem plate is represented simply by a separate strand of crushed protoxylem elements.

It was thought possible at first that the reduction by fusion and disappearance might be successive stages in the acquirement of persistent triarchy. If this were true, however, one would expect the dying away of a pole to occur always low down in the root, since it would constitute the stage immediately preceding complete and persistent triarchy. This is, however, not the case, for in some instances among the tetracotylous seedlings the tetrarch stage is reduced to a triarch one in the hypocotyl by the dying away of a xylem plate, whilst reduction by fusion of poles is found in the root.

All things considered it seems preferable to regard this type of reduction in the number of poles as either a subsidiary line of evolution or as due to a sudden dominance of the ancestral hypocotyledonary diarchy over the newly acquired triarch symmetry.

It will be obvious, however, that though there is a considerable body of evidence which lends support to our hypothesis concerning the origin of polycotyly, there are at the same time a number of difficulties which present themselves. In the first place, it may be suggested that there are structures which are obviously half bundles of a cotyledon which each show double structure, as for example in the Calycanthaceae, Fagaceae, Euphorbiaceae, Sapotaceae, Ebenaceae, and certain of the Rosaceae, in which the so-called diagonal arrangement occurs. A careful consideration of these will show an essential difference however, since in the majority of cases a very evident median protoxylem exists between the paired double bundles, and even in the extreme case of Calycanthus Chauveaud has demonstrated the existence of such a strand in the very young state. No trace of a median protoxylem has ever been found by us between the twin double bundles in the Cheiranthus seedlings, and such might reasonably have been expected had they originated from modified half bundles. It must be admitted, however, that no median protoxylem appears in the separate parts of the split cotyledons between the two collateral bundles of the type $a$ seedling, which are recognized as half bundles. There is, however, a further important distinction, for, in the groups named above, the constituent halves invariably constitute a divergent system, and in no case do they unite at a lower level, while in the type $\beta$ Cheiranthus seedlings the bundles form a convergent system, and in many cases unite either in the hypocotyl or in the root. 
Another difficulty is found, not so much in Cheiranthus itself as in the application of the theory to seedlings of other genera. Thus Hill and de Fraine (10) describe a seedling of Silene Schafta which, although dicotylous, is yet triarch throughout, the larger of the two cotyledons possessing two double bundles. The same feature, though not in so pronounced a form, has been met with by one of us in polycotylous seedlings of Centranthus nubra. These seedlings are obviously of type $\beta$, and the structure of the cotyledons may possibly be due to a fusion or partial fusion of the parenchymatous tissues of the lamina having followed the division of the cotylar apex. Such a fusion is quite probable when one considers the close proximity of the two cotyledons during their development, and the plastic character of the tissues during the early stages. A second possible explanation is that whilst the plerome and the outer half of the periblem and dermatogen have retained their full activity subsequent to apical division, the activity of the inner half of the periblem and dermatogen has been completely suppressed, since a less complete reduction in the activity of these tissues is often apparent in cotyledons which show incomplete division.

A difficulty of another kind arises in connexion with Lotus corniculatus and Carmichaelia australis, two Leguminosae described by Compton (3).

Lotus corniculatus is of considerable interest, since the dicotyl exhibits a trimerous symmetry due to the persistence of one of the lateral strands from each cotyledon in the hypocotyl, these fusing to form a third pole; and a similar state of affairs is found in Carmichaelia australis. In the former species Compton describes a hemitricotyl in which root and hypocotyl showed triarch symmetry, but which obviously corresponds to our type $\beta$. The tricotylous specimens of Lotus corniculatus and Carmichaelia also show a trimerous symmetry; but we are inclined to regard this as not homologous with that of the dicotyl and hemitricotyl, but rather as an instance of the complete suppression of the relatively feeble pole of the triarch system derived from the fused laterals, and its replacement by the robust median strand derived from the midrib of the third cotyledon.

This view is supported by an examination of the normal seedling structure of the genus Lotus, and in fact of the whole tribe Loteae. In Lotus the cotyledons each contain a median double bundle and two laterals, from which in L. tetragonolobus and $L$. Requieni tetrarchy results, while in $L$. corniculatus triarchy is characteristic of the root. This is evidently due to the suppression of one of the 'paired laterals', and it is noteworthy that the other is in process of suppression. Other members of the tribe Loteae show similar features, e.g. Anthyllis tetraphylla is tetrarch, while A. vulneraria and $A$. Barba-Fovis are diarch, and another member, Dorycnium hirsutum, may be either tetrarch, triarch, or diarch [(3) pp. 35-9]. A similar tendency to the suppression of laterals is also found in tribe Galegeae, 
sub-tribe Robiniinae [(3) pp. 4I-5], to which Carmichaelia australis belongs. In view of these facts it seems reasonable to suppose that the robust strand of the new cotyledon would supplant the feeble pole derived from the laterals.

It has not been felt to be necessary to deal with the class of cotyledons termed 'subsidiary' by Hill and de Fraine since, they have no bearing on our work. This group is left in rather an ill-defined condition, and seems to contain all cases which cannot be definitely classed as 'whole' or half cotyledons. Although they do not make any definite statement it is evident that they include in this class at least two types of cotyledon :

(a) displaced foliage leaves;

(b) cotyledons formed by the splitting off of tissues laterally from the normal cotyledon, the splitting being either symmetrical or asymmetrical.

The variety of behaviour, however, is so great, and the number of seedlings of each species examined is relatively so small, that on the present evidence it seems impossible to put forward any comprehensive explanation of the phenomena found in these seedlings. A more thorough investigation of two or three species seems to be called for, and such an investigation is now in progress.

\section{SUMMARY。}

I. The vascular anatomy of a series of wallflower seedlings showing cotyledonary abnormality ranging from hemitricotyly to tetracotyly is described.

2. This is believed by us to indicate at least two, and possibly three, methods of cotyledonary increase :

(I) By cotyledonary fission;

(2) By dichotomy of the growing point of the cotyledon; and

(3) Much more doubtfully, by the downward displacement of one or more epicotyledonary leaves.

3. It is finally shown that previous work on schizocotyly is capable of interpretation on this basis, and affords illustrations of all these types of increase.

The authors are much indebted to Dr. T. G. Hill for his courteous permission to examine a number of slides of Gymnosperm seedlings, and also to Professor Carr, University College, Nottingham, who granted every facility for the investigation. 


\section{BIBLIOGRAPHY.}

1. Chauveaun, G.: L'appareil conducteur des plantes vasculaires. Ann. Sci. Nat., Bot., igri.

2. Compton, R. H. : Theories of the Anatomical Transition from Root to Stem. New Phyt., I 9 I 2.

3. $:$ An Investigation of the Seedling Structure in the Leguminosae. Jour. Linn. Soc. (Bot.), I9I 2.

4. : Syncotyly and Schizocotyly. Ann. Bot., I9I3.

5. Davey, A. J.: Seedling Anatomy of certain Amentiferae. Ann. Bot., 1916.

6. Dangeard, P.: Recherches sur les plantules des Conifères. Le Botaniste, $3^{e}$ sér., 1892.

7. de Fraine, E.: The Seedling Structure of certain Cactaceae. Ann. Bot., I9Io.

8 Guillaumin, A. : Germinations anormales. Bull. de la Soc. Bot. de France, igi I.

9. Hill, T. G., and DE Fraine, E. : On the Seedling Structure of Gymnosperms. I to IV. Ann. Bot., I908-10.

10. - The Seedling Structure of Centrospermae. Ann. Bot., I9I 2.

11. - : The Influence of the Structure of the Adult Plant upon the Seedling. New Phyt., I9I 2.

12. - The Structure of Seedlings. Ann. Bot., 19I3.

13. - The Classification of Seed-leaves. Ann. Bot., 1914.

14. LÉGer, L. J.: Note sur les germinations anormales d'Acer platanoides. Bull. Soc. Linn. de Normandie, 1890.

15. Lee, E.: Observations on the Seedling Anatomy of certain Sympetalae, Pt. II. Ann. Bot., I9I 4.

16. Masters, W. T.: Comparative Anatomy, \&c., of the Coniferae. Jour. Linn. Soc. (Bot.), i 891.

17. Scotr, D. H. : Structural Botany, I. 8th edition.

18. Smith, W.: Anatomy of some Sapotaceous Seedlings. Trans. Linn. Soc., ser. II, Bot., vol. vii, 1909 .

19. Thiselton-Dyer, W. T. : Morphological Notes. VIII. On Polycotyledony. Ann. But., I 902.

20. Thomas, E. N.: Seedling Anatomy of Ranales, Rhoeadales, and Rosales. Ann. Bot., I9I 4.

21. DE VRIES, H.: Über tricotyle Rassen. Ber. der Deutsch. Bot. Ges., I902.

22. Winkler, A. : Anormale Keimungen. Abh. d. Bot. Ver. Brandenburg, I 894.

23. Wright, H. : The Genus Diospyros in Ceylon. Ann. Roy. Bot. Gard. Peradeniya, vol. ii, I904. 


\section{$2 \mathrm{BHL}$ Biodiversity Heritage Library}

Holden, Henry Smith and Bexon, Dorothy. 1918. "Observations on the anatomy of teratological seedlings. I. On the anatomy of some polycotylous seedlings of Cheiranthus cheiri." Annals of botany 32, 513-530. https://doi.org/10.1093/oxfordjournals.aob.a089689.

View This Item Online: https://www.biodiversitylibrary.org/item/238284

DOI: https://doi.org/10.1093/oxfordjournals.aob.a089689

Permalink: https://www.biodiversitylibrary.org/partpdf/320231

\section{Holding Institution}

Smithsonian Libraries

\section{Sponsored by}

Biodiversity Heritage Library

\section{Copyright \& Reuse}

Copyright Status: Not in copyright. The BHL knows of no copyright restrictions on this item.

This document was created from content at the Biodiversity Heritage Library, the world's largest open access digital library for biodiversity literature and archives. Visit BHL at https://www.biodiversitylibrary.org. 